\title{
Perspectivas da terapia gênica
}

\author{
Perspectives of gene therapy
}

Eugenia Costanzi-Strauss', Bryan E. Strauss²

Costanzi-Strauss E, Strauss BE. Perspectivas da terapia gênica/Perspectives of gene therapy. Rev Med(São Paulo). 2015 out.-dez:;94(4):211-22.

RESUMO: O conceito de terapia gênica é simples: introduzir material genético na célula com o objetivo de interceder na progressão de uma doença. Mesmo com uma definição de fácil entendimento, na verdade o campo de estudo da terapia gênica é rico em tecnologias inovadoras, conhecimentos e práticas interdisciplinares. $\mathrm{O}$ desenvolvimento e aplicação de terapia gênica encontram desafios significativos iguais como qualquer tratamento ainda em fase experimental, mas também enfrentam dificuldades próprias devidas ao uso de material biológico como agente farmacológico. Esta pequena revisão apresenta alguns conceitos básicos sobre a tecnologia e aplicação de terapia gênica e serve como base para uma discussão sobre o importante papel da associação entre pesquisa básica e clínica no desenvolvimento desta nova abordagem terapêutica. A contribuição dos conhecimentos dos especialistas em aspectos básicos e clínicos permite que tanto a tecnologia quanto a aplicação de terapia gênica em pacientes rapidamente recebam os benefícios do progresso da ciência. No Brasil, a terapia gênica se encontra em fase precoce quando comparado com vários países ao redor do mundo, porém nossos avanços são significativos e existem excelentes perspectivas de crescimento.

Descritores: Terapia genética; Vetores de doenças; Técnicas de transferência de gênes; Pesquisa médica translacional; Projetos de pesquisa/normas.

\begin{abstract}
The concept of gene therapy is really quite simple: delivery of genetic material to cells with the objective of impacting the progression of a disease. Even with this easy to understand definition, the field of gene therapy is actually rich in technologic innovations and interdisciplinary knowledge and practice. The development and application of gene therapy encounter significant challenges just as is seen with any experimental treatment, but also encounters additional difficulties that are particular to the use of biological material as a pharmacological agent. This short review will present a few basic concepts about the technology and application of gene therapy and will provide the basis for discussing the important role that is played by the association of basic and clinical researchers during the development of these new therapeutic approaches. The contribution of knowledge by specialists in the laboratory and clinical aspects permits the rapid progress of both technology and its application as gene therapy in patients. In Brazil, gene therapy is still at an early phase of development as compared to many countries around the world, yet our advances are significant and we have excellent perspectives for growth in this area.
\end{abstract}

Keywords: Genetic therapy; Disease vectors; Gene transfer techniques; Translational medical research; Research design/ standards.

1. Bacharel em Ciências Biológicas/Modalidade Médica, Universidade Federal de São Paulo, Mestrado em Biologia Molecular na Universidade Federal de São Paulo, Doutorado em Biologia Molecular na Universidade Federal de São Paulo. É atualmente coordenadora do Laboratório de Terapia Gênica e docente no Departamento de Biologia Celular e do Desenvolvimento, Instituto de Ciências Biomédicas, Universidade de São Paulo, São Paulo, Brasil. E-mail: ecostanz@usp.br

2. Bacharel em Bioquímica/Biologia Molecular na Universidade de Califórnia, Santa Barbara, EUA; Doutorado em Patologia Molecular da Universidade de Califórnia, San Diego, EUA; Livre Docente em Oncologia-Área Básica pelo Departamento de Radiologia e Oncologia da FM-USP; É atualmente coordenador do Laboratório de Vetores Virais, Centro de Investigação Translacional em Oncologia/LIM24, Instituto do Câncer do Estado de São Paulo, Faculdade de Medicina, Universidade de São Paulo, São Paulo, Brasil.E-mail: bstrauss@usp.br, bryan.strauss@hc.fm.usp.br.

Endereço para correspondência: Bryan E. Strauss. Centro de Investigação Translacional em Oncologia/LIM24, Instituto do Câncer do Estado de São Paulo. Av. Dr. Arnaldo, 251 - $8^{\circ}$ Andar. São Paulo, SP. CEP: 01246-000. 


\section{INTRODUÇÃO}

terapia gênica não é uma ideia nova. A noção de alterar o fenótipo de uma doença utilizando transferência gênica já existia mesmo antes do surgimento das ferramentas de DNA recombinante. A primeira tentativa de utilização de material genético para tratar uma doença aconteceu em meados dos anos 60, antes do estabelecimento das recomendações para manipulação de DNA com segurança. A estratégia escolhida foi tratar hiperargininemia com a aplicação de vírus do papiloma de Shope, conhecido por expressar arginase, mas este ensaio pioneiro não atingiu benefício clínico ${ }^{1}$. Os primeiros relatos de construção de vetores plasmidiais aconteceram no início dos anos $70^{2}$ e simultaneamente foram descritos os parâmetros necessários, mas ainda não existentes na época, para colocar a terapia gênica em prática $^{3}$. Nos anos 80 a tecnologia do DNA recombinante contagiou a pesquisa biomédica e pela primeira vez um vetor recombinante foi testado em humanos como veículo de modificação do genoma. O objetivo deste protocolo experimental foi tratar a $\beta$-talassemia transferindo o gene de $\beta$-globina para as células do paciente ${ }^{4}$. Felizmente, os pacientes não sofreram com o tratamento, mas também não experimentaram benefício, mas o pesquisador responsável por este estudo foi severamente censurado pelo fato de ter executado um novo protocolo clínico sem autorização. Estes exemplos revelaram um ponto crítico: a consequência de não ter intensa investigação pré-clínica básica antes de experimentar o novo tratamento nos pacientes.

Por volta de 1990 foi realizado nos EUA o primeiro protocolo clínico de terapia gênica com autorização do FDA (Food and Drug Administration) destinado ao tratamento de dois pacientes portadores de imunodeficiência primária ${ }^{5,6}$. O protocolo foi relativamente bem sucedido, sem efeitos colaterais e uma das crianças foi praticamente curada da anomalia ${ }^{6}$. Desde então, a experiência com terapia gênica cresceu consideravelmente. Hoje, com seus 25 anos de experimentação clínica, já foram executados e/ou autorizados mais do que 2140 protocolos clínicos de terapia gênica ao redor do mundo ${ }^{7}$. Existem claros exemplos de sucesso de terapia gênica para o tratamento de diversas doenças e também algumas situações isoladas onde foram constatados efeitos adversos. Independente do resultado do ensaio, cada tentativa de terapia gênica representa uma oportunidade de aprendizagem e de benefício para os pacientes. Como discutido aqui, a chave para o progresso de terapia gênica está na interação de pesquisadores básicos e clínicos, cada um contribuindo com conhecimentos especializados, mas cuja somatória conduz a meta comum de oferecer novas opções para o tratamento de doenças onde terapias tradicionais têm eficácia aquém do desejado.

\section{Conceitos básicos}

A terapia gênica é um assunto que engloba não só pesquisa básica e clínica, mas também considerações éticas, biossegurança e aspectos regulatórios. A efetivação de terapia gênica requer uma gama de tecnologias que permite a produção de material biológico em escala e com qualidade apropriada para aplicação em seres humanos. Ou seja, não é simplesmente um método, mas sim o desenvolvimento de um biofármaco.

Em termos gerais, a terapia gênica usa a transferência de uma sequência de ácido nucléico para células do paciente. A transferência pode ser realizada por métodos que envolvem um vetor viral ou não-viral e o material genético pode ser um gene, tipicamente na forma de cDNA que codifica uma proteína funcional capaz de alterar um processo celular. Alternativamente sequências não-codificantes (RNA de interferência ou sequência antisenso) e outras versões de ácidos nucléicos (aptâmeros ou RNA mensageiro) produzidos nos laboratórios também podem ser introduzidos diretamente nas células alvo sem a necessidade de um vetor. A rota da transferência gênica pode ser in situ (diretamente no organismo) ou ex vivo [as células dos pacientes são modificadas fora do organismo (no laboratório) e posteriormente implantadas no paciente]. Hoje, a tecnologia de transferência gênica ainda não permite aplicação sistêmica do vetor de maneira eficaz e segura. Por motivos éticos, o alvo da terapia gênica não pode incluir células germinais, a modificação genética obrigatoriamente só pode atingir as células somáticas dos indivíduos. Em outras palavras, os benefícios clínicos da intervenção genética não são transmitidos para os descendentes dos pacientes, que passam a ser considerados como casos novos.

Uma das promessas da terapia gênica é tratar a raiz da doença, melhor ainda, atingir a alteração genética responsável pela patologia. Os tratamentos mais simples são os de doenças monogênicas, onde um único gene mutado causa uma alteração específica em um processo celular. Por exemplo, na hemofilia tipo B, a transferência do cDNA do fator de coagulação IX re-estabelece a expressão da proteína normal e reverte o quadro clínico. Muitas doenças têm origem complexa, como hipertensão e câncer, onde um grande conjunto de genes pode contribuir para a patologia. Nestes casos, o desafio está na escolha de um (ou mais) gene(s) que pode(m) controlar a progressão da doença. $\mathrm{O}$ uso de terapia gênica para combater doenças infecciosas, como HIV, também tem sido realizado e representa um grau de complexidade intermediário, porque neste caso o agente causador da doença é bem conhecido e caracterizado, porém ainda resta desenvolver a estratégia do seu combate.

Nos cenários descritos aqui, a terapia gênica representa uma complementação para função celular, ou 
seja, acréscimo de uma sequência exógena no genoma celular, mas que continua expressando a versão endógena do gene mutante. Hoje, novas tecnologias que prometem literalmente corrigir o defeito genético estão surgindo. Esta tecnologia, coletivamente conhecida como genome editing, é capaz de alterar uma única base no DNA ou repor uma sequência mais extensa de DNA. Assim, a mutação causadora da doença desaparece do genoma. Alternativamente, o genome editing pode ser utilizado para inibir expressão gênica, uma aplicação interessante é apagar a expressão do co-receptor do HIV, CCR5, prevenindo infecção ${ }^{8,9}$. Um problema sério com as tecnologias existentes de genome editing é o risco de indução de alterações fora do alvo específico, isto representa uma oportunidade para criar na célula tratada novas e não desejadas mutações de consequências desconhecidas. Outro problema fundamental está na eficiência de desempenho da tecnologia e do processo de transferência gênica ${ }^{10}$. Por enquanto, as estratégias de genome editing estão sendo testadas em cultura de células e modelos animais, mas os resultados são promissores e no futuro a terapia gênica talvez alcance a meta de literalmente corrigir o genoma celular.

\section{Vetores de transferência gênica}

Uma grande variedade de vetores está sendo empregada nos protocolos de terapia gênica, incluindo vírus recombinantes, plasmídeos e nanopartículas ${ }^{11,12}$. A escolha do vetor depende de fatores relacionados com a própria doença, o gene terapêutico, o tecido alvo e a rota de transferência. Exemplificando, os requerimentos para o vetor utilizado no tratamento de hemofilia são diferentes dos vetores desenhados para o tratamento do câncer. No caso de hemofilia o benefício terapêutico depende da expressão duradora do fator de coagulação, que deve ser preservado mesmo após sucessivas divisões das células tratadas ${ }^{13}$. Em contraste, o tratamento de câncer tem como alvo a morte da célula tumoral, agora a expressão permanente do gene terapêutico não é necessária e pode até ser perigosa e prejudicar as células saudáveis ${ }^{14}$. Para o tratamento de doenças hematológicas, como $\beta$-talassemia, a modificação precisa ser realizada na célula apropriada, como as células tronco hematopoiéticas, um procedimento facilmente realizado ex vivo, mas o vetor de transferência deve garantir a expressão do gene terapêutico, $\beta$-globina, somente nos eritrócitos ${ }^{15}$. Em resumo, um vetor bem desenhado tem grande impacto no desempenho da transferência gênica e no sucesso da abordagem terapêutica.

Na Tabela 1 encontram-se algumas informações sobre os principais vetores utilizados nos estudos de terapia gênica. Não serão discutidos aqui detalhes de como construir, produzir e manipular os vetores, estas informações podem ser encontradas na literatura ${ }^{12,14}$. Alguns pontos merecem destaque, principalmente os relacionados com a segurança. Em geral os vetores virais recombinantes possuem mecanismos moleculares que impedem a replicação viral nas células do paciente. $O$ vírus recombinante é capaz de transduzir a célula alvo e expressar o transgene, mas não pode replicar e consequentemente não infecta outras células. Em comparação, vírus selvagens replicam após infectar uma célula e espalham sua progênie para outras células e até mesmo para outros indivíduos.

Tabela 1: Propriedades de alguns vetores comumente utilizados em protocolos clínicos de terapia gênica

\begin{tabular}{|c|c|c|c|c|c|}
\hline Vetor & Retrovírus & Lentivírus & Adenovírus & $\begin{array}{l}\text { Vírus adeno- } \\
\text { associado }\end{array}$ & Plasmídeo \\
\hline $\begin{array}{l}\text { Título, partículas } \\
\text { virais } / \mathrm{ml}^{\mathrm{a}}\end{array}$ & $10^{9}$ & $10^{9}$ & $10^{12}$ & $10^{12}$ & NA \\
\hline Rota de transferência & Ex vivo & Ex vivo & In situ & In situ & In situ \\
\hline $\begin{array}{l}\text { Integração no genoma } \\
\text { do hospedeiro }\end{array}$ & Sim & Sim & Não & Raramente & Não \\
\hline $\begin{array}{l}\text { Expressão a longo } \\
\text { prazo }\end{array}$ & Sim & Sim & Não & Sim & Não \\
\hline $\begin{array}{l}\text { Resposta imune contra } \\
\text { proteínas virais }\end{array}$ & Não & Não & Sim & $\begin{array}{l}\text { Sim, mas não } \\
\text { severo }\end{array}$ & Não \\
\hline Protocolos clínicos ${ }^{\mathrm{b}}$ & 417 & 114 & 480 & 137 & 502 \\
\hline Aplicação típica & $\begin{array}{l}\text { Sistema } \\
\text { hematopoiético }\end{array}$ & $\begin{array}{l}\text { Sistema } \\
\text { hematopoiético }\end{array}$ & Cancer, vacinas & $\begin{array}{l}\text { Hemofilia, fibrose } \\
\text { cística }\end{array}$ & $\begin{array}{l}\text { Cardiovascular, } \\
\text { cancer, vacinas }\end{array}$ \\
\hline
\end{tabular}

a: título após concentração/purificação da preparação viral

b: veja http://www.abedia.com/wiley/

NA: não aplicável 
A manipulação de vírus recombinante é baseada principalmente em plasmídeos que codificam os componentes necessários para a montagem da progênie viral $^{12,14}$. A engenharia do vetor garante através de um sistema de complementação que a replicação do vírus ocorra somente no laboratório, processo essencial para produção da partícula viral recombinante. Simplificadamente apenas no laboratório é que todos os componentes necessários para formação da partícula viral se encontram, incluindo plasmídeos e células empacotadoras, complementando assim a expressão dos genes necessários para a replicação e construção da partícula viral. As células do paciente que recebem o vírus recombinante passam a expressar o gene terapêutico, mas não propagam o vírus devido à falta de elementos críticos da maquinaria de replicação viral.

Tipicamente, o transgene (gene terapêutico) é inserido no vetor na forma de cDNA e sua expressão segue as regras fundamentais da biologia molecular. $\mathrm{O}$ desenho do vetor deve incluir todas as sequências regulatórias necessárias para garantir a expressão do material genético, incluindo um promotor (que direciona a transcrição) e um sinal de poliadenilação (que define o final do transcrito e encaminha a tradução). Este arranjo básico representa uma oportunidade de direcionamento, ou seja, onde, quanto e quando o transgene será expresso. O uso de um promotor tecido específico, por exemplo da $\beta$-globina, limita a expressão do gene terapêutico apenas aos eritrócitos do paciente. Também existem promotores responsivos para condições fisiológicas, por exemplo os promotores que respondem a condição de hipóxia, limitando a expressão do transgene ao quadro de isquemia. Outros exemplos podem ser encontrados na literatura ${ }^{16}$.

A interação do vetor com receptores na superfície da célula alvo também representa uma oportunidade para modificar o tropismo viral. Os vetores derivados do adenovírus sorotipo 5 , somente podem transduzir células que exibem o receptor específico Coxsackie Adenovirus Receptor (CAR). Células sem CAR não são transduzidas pelo adenovírus 5, mas o vetor adenoviral recombinante pode ser modificado com finalidade de criar especificidade para um tipo celular (como célula tumoral) ou de ampliar o tropismo do vetor (transdução de células sem CAR) ${ }^{12,14}$. Por exemplo, modificando o vírus com a inclusão do tripeptídeo RGD (argenina-glicina-ácido aspártico) permitirá a transdução de grande grupo de células que expressam integrinas ${ }^{17}$.

Outra estratégia é simplesmente usar o vetor viral como o próprio agente de tratamento. Vírus oncolíticos possuem extensa engenharia que restringe a infecção e replicação, assegurando que estes processos ocorram somente em células alvo, como células tumorais. Com esta abordagem, a célula tumoral se torna uma fábrica de novas partículas virais que são liberadas após lise celular. Estas novas partículas, por sua vez, infectam mais células tumorais, amplificando o processo lítico e consequentemente destruindo as células tumorais.
Células saudáveis não permitem a replicação do vírus oncolítico e não sofrem com sua presença. Como o nome indica, os vírus oncolíticos destroem particularmente células de câncer, a principal exigência funcional do sistema é associar uma característica presente apenas nas células tumorais com o programa de replicação viral. Por exemplo, um vetor oncolítico capaz de replicar e lisar apenas as células com p53 mutada ou células sem pRb ${ }^{18,19}$. Outros benefícios do uso de vírus oncolíticos incluem o mecanismo de morte celular independente de apoptose e a indução de uma resposta imunológica adaptativa. Os vírus oncolíticos também podem ser utilizados para transferir um gene funcional, como GM-CSF, reforçando a resposta imunológica anti-tumoral ${ }^{12,14,18,19}$.

\section{Exemplos de sucesso}

Como detalhado na Tabela 2 , já foram descritos exemplos claros de sucesso da terapia gênica para tratamento de uma ampla variedade de doenças. De maneira geral, o tratamento de doenças monogênicas, especialmente aquelas onde o tratamento pode ser realizado na linhagem tronco hematopoiética, tem resultado em benefícios para os pacientes. Um dos maiores sucessos da terapia gênica está no tratamento da imunodeficiência severa combinada associada à deficiência em adenosina deaminase, onde $90 \%$ dos pacientes tratados foram beneficiados e sem nenhum relato de efeito adverso ${ }^{20,21}$.Uma das consequências deste progresso foi uma proposta que surgiu durante a última reunião da Sociedade Europeia de Terapia Gênica e Celular, a qual considera terapia gênica como tratamento de primeira linha para doenças raras. Mais ainda, o International Rare Disease Research Consortium (IRDiRC: www.irdirc.org) estabeleceu meta de atingir 200 protocolos até o ano de 2020. No campo da oncologia clínica o destaque recente envolve os espetaculares resultados obtidos com receptor quimérico de antígeno (CAR, chimeric antigen receptor) em células $\mathrm{T}$ desenvolvido para o tratamento de leucemias de células $\mathrm{B}^{22}$.

Vários vetores virais para terapia gênica já foram aprovados para comercialização (Tabela 3) ${ }^{23,24}$. Entre os que estão no mercado merecem destaque o Gendicine (adenovírus portador do cDNA de p53 para terapia gênica do câncer) produzido e comercializado na China desde 2003. No lado tecnológico, o Gendicine serve de exemplo de que a produção e distribuição de vírus recombinante para o tratamento gênico estão dentro do alcance industrial ${ }^{25}$. No lado científico, as informações sobre o desempenho desta abordagem ainda são escassas, entretanto protocolos clínicos continuam a relatar o sucesso do Gendicine, especialmente quando a terapia gênica é combinada com quimioterapia no tratamento de câncer de cabeça e pescoço $^{26}$. Entre 2003 e 2007, mais do que 7000 pessoas já foram tratadas com Gendicine ${ }^{25}$. Até agora, não existem relatos de efeitos adversos com o uso do Gendicine, além de sintomas de gripe, uma observação que chama atenção quando comparada com os efeitos colaterais do uso de quimioterapias tradicionais. 
Costanzi-Strauss E, Strauss BE. Perspectivas da terapia gênica.

Tabela 2: Exemplos de sucessos e problemas no uso clínico de terapia gênica

\section{Modificação ex vivo de células tronco hematopoiéticas}

\begin{tabular}{|c|c|c|c|c|}
\hline Doença & Vetor/gene & Avanço & Limitações & Referências \\
\hline $\begin{array}{l}\text { Imunodeficiência severa } \\
\text { combinada-deficiência } \\
\text { de adenosine deaminase } \\
\text { (ADA-SCID) }\end{array}$ & Retrovírus/ADA & $\begin{array}{l}\text { Reversão do quadro } \\
\text { clínico em } 90 \% \text { dos } \\
\text { tratados }\end{array}$ & & $\begin{array}{l}\text { Aiuti et al. }{ }^{43}, \text { Gaspar et } \\
\text { al. }{ }^{44} \text {, Candotti et al. }{ }^{45} \text {, } \\
\text { Gaspar, }^{46}\end{array}$ \\
\hline $\begin{array}{l}\text { Imunodeficiência severa } \\
\text { combinada-deficiência de } \\
\text { IL2RG (X-SCID) }\end{array}$ & Retrovírus/IL2RG & $\begin{array}{l}\text { Reversão do quadro } \\
\text { clínico em } 90 \% \text { dos } \\
\text { tratados }\end{array}$ & $\begin{array}{l}\text { Efeito adverso severo } \\
\text { devido o uso do } \\
\text { retrovírus. Cinco casos } \\
\text { de leucemia, incluindo } \\
\text { a morte de um destes } \\
\text { pacientes. }\end{array}$ & $\begin{array}{l}\text { Zhang et al }{ }^{47}, \text { Strauss; } \\
\text { Costanzi-Strauss }^{48}\end{array}$ \\
\hline $\begin{array}{l}\text { Doença granulomatosa } \\
\text { crônica ligada ao X } \\
\text { (X-CGD) }\end{array}$ & Retrovírus/gp91 phox & $\begin{array}{l}\text { Reversão do quadro } \\
\text { clínico por um tempo } \\
\text { limitado }\end{array}$ & $\begin{array}{l}\text { Mielodisplasia em dois } \\
\text { pacientes }\end{array}$ & Ott et al. ${ }^{49}$ \\
\hline $\begin{array}{l}\text { Sindrome Wiscott-Aldrich } \\
\text { (WAS) }\end{array}$ & Retrovírus/WASP & $\begin{array}{l}\text { Reversão do quadro } \\
\text { clínico em } 90 \% \text { dos } \\
\text { tratados durante um } \\
\text { tempo limitado }\end{array}$ & $\begin{array}{l}\text { Efeito adverso severo } \\
\text { devido o uso do } \\
\text { retrovírus. Sete casos de } \\
\text { leucemia. }\end{array}$ & $\begin{array}{l}\text { Hacein-Bey Abina et } \\
\text { al. } .^{50}\end{array}$ \\
\hline $\begin{array}{l}\text { Sindrome Wiscott-Aldrich } \\
\text { (WAS) }\end{array}$ & Lentivírus/WASP & $\begin{array}{l}\text { Reversão do quadro } \\
\text { clinico em } 6 \text { dos } 7 \\
\text { pacientes tratados }\end{array}$ & & $\begin{array}{l}\text { Hacein-Bey Abina et } \\
\text { al. } .^{50} \text {, Aiuti et al. }{ }^{51}\end{array}$ \\
\hline$\beta$-talessemia & Lentivírus/ $\beta$-globina & $\begin{array}{l}\text { Reversão do quadro } \\
\text { clínico }\end{array}$ & $\begin{array}{l}\text { Expansão clonal, porém } \\
\text { sem efeito adverso. }\end{array}$ & $\begin{array}{l}\text { Cavazzana-Calvo et } \\
\text { al. } .^{52}\end{array}$ \\
\hline $\begin{array}{l}\text { Adrenoleucodistrofia } \\
\text { ligada ao X (X-ALD) }\end{array}$ & Lentivírus/ABCD1 & $\begin{array}{l}\text { Retardo na progressão } \\
\text { da doença }\end{array}$ & & Cartier et al. ${ }^{53}$ \\
\hline $\begin{array}{l}\text { Leucodistrofia } \\
\text { metacromatica (MLD) }\end{array}$ & Lentivírus/ARSA & $\begin{array}{l}\text { Reversão do quadro } \\
\text { clínico em } 3 / 9 \\
\text { pacientes }\end{array}$ & & Biffi et al. ${ }^{54}$ \\
\hline
\end{tabular}

Exemplos de sucesso quando o tratamento foi realizado in situ

\begin{tabular}{|c|c|c|c|c|}
\hline Melanoma & $\begin{array}{l}\text { T-Vec, vírus herpes } \\
\text { oncolítico }\end{array}$ & $\begin{array}{l}\text { Resposta completa } \\
\text { ou parcial que durou } \\
\text { pelo menos } 6 \text { meses } \\
\text { em } 16 \% \text { dos pacientes } \\
\text { (compara com } \\
\text { resposta de } 2 \% \text { nos } \\
\text { braços controles) }\end{array}$ & & $\begin{array}{l}\text { Sheridan et al. }{ }^{55} \\
\text { Andtbacka et al. }\end{array}$ \\
\hline $\begin{array}{l}\text { Amaurose congênita de } \\
\text { Leber (Leber's Congenital } \\
\text { Amaurosis) }\end{array}$ & $\begin{array}{l}\text { AAV/RPE65 aplicado } \\
\text { diretamente na retina }\end{array}$ & $\begin{array}{l}\text { Ganho significativo } \\
\text { em visão }\end{array}$ & $\begin{array}{l}\text { Foi documentado } \\
\text { decréscimo do efeito } \\
\text { terapêutico } 2 \text { a } 3 \text { anos } \\
\text { após tratamento. }\end{array}$ & $\begin{array}{l}\text { Bainbridge et al. }{ }^{57} \text {, } \\
\text { Maguire et al. }\end{array}$ \\
\hline Leucemia de células B & $\begin{array}{l}\text { CAR T cell, células T } \\
\text { modificadas com um } \\
\text { receptor quimérico } \\
\text { para o antígeno } \\
\text { CD19 }\end{array}$ & $\begin{array}{l}90 \%(27 / 30) \text { dos } \\
\text { pacientes entram em } \\
\text { remissão, } 22 / 27 \text { livre } \\
\text { de doença residual }\end{array}$ & $\begin{array}{l}\text { Síndrome de lise } \\
\text { tumoral; recidiva de } 7 / 27 \\
\text { pacientes; pressão seletiva } \\
\text { para células CD19- } \\
\text { negativas }\end{array}$ & $\begin{array}{l}\text { Maude et al. } \\
\text { Chicaybam; } \\
\text { Bonamino }^{60}\end{array}$ \\
\hline
\end{tabular}


Costanzi-Strauss E, Strauss BE. Perspectivas da terapia gênica.

Tabela 3: Produtos para terapia gênica aprovados para distribuição comercial

\begin{tabular}{|c|c|c|c|c|}
\hline $\begin{array}{l}\text { Local (ano/ } \\
\text { agência) }\end{array}$ & Empresa & Vetor & Descrição & Referências \\
\hline $\begin{array}{l}\text { China }(2003 / \\
\text { SFDA) }\end{array}$ & $\begin{array}{l}\text { Shenzhen } \\
\text { GentechSiBiono }\end{array}$ & Gendicine (Ad-p53) & $\begin{array}{l}\text { Vetor adenoviral não-replicativo } \\
\text { expressando p53 para o tratamento de } \\
\text { câncer da cabeça e pescoço }\end{array}$ & Jia; Kling ${ }^{61}$, Peng et al. ${ }^{62}$ \\
\hline $\begin{array}{l}\text { China (2005/ } \\
\text { SFDA) }\end{array}$ & $\begin{array}{l}\text { Shanghai } \\
\text { Sunway Biotech }\end{array}$ & $\begin{array}{l}\text { Oncorine/H101 } \\
\text { (Onyx-015) }\end{array}$ & $\begin{array}{l}\text { Adenovírus que replica } \\
\text { condicionalmente devido uma } \\
\text { mutação no gene E1b que confere } \\
\text { oncolise tumor específico. Aprovado } \\
\text { para tratamento de câncer da cabeça } \\
\text { e pescoço }\end{array}$ & Jia; Kling ${ }^{61}$, Peng et al. ${ }^{62}$ \\
\hline $\begin{array}{l}\text { Filipinas } \\
\text { (2007/BFAD) }\end{array}$ & Epeius & Rexin-G* & $\begin{array}{l}\text { Retrovetor não replicativo } \\
\text { direcionado a matriz extracelular } \\
\text { (colágeno) e expressando um mutante } \\
\text { de ciclina G que provoca morte } \\
\text { celular. Aprovado para tratamento de } \\
\text { tumores sólidos }\end{array}$ & Gordon; Hall ${ }^{63,64}$ \\
\hline $\begin{array}{l}\text { European } \\
\text { Union }(2012 / \\
\text { EMA-CHMP) }\end{array}$ & $\begin{array}{l}\text { Amsterdam } \\
\text { Molecular } \\
\text { Therapeutics }\end{array}$ & $\begin{array}{l}\text { Glybera } \\
\text { (alipogenetiparvovec) }\end{array}$ & $\begin{array}{l}\text { Vírus adeno-associado codificando } \\
\text { o variante Ser(447)X do gene } \\
\text { lipoproteína lipase humano (LPL) } \\
\text { para o tratamento da deficiência de } \\
\text { LPL hereditária }\end{array}$ & $\begin{array}{l}\text { Miller }{ }^{65}, \text { Burnett; } \\
\text { Hooper }^{66}\end{array}$ \\
\hline $\begin{array}{l}\text { EUA (2015/ } \\
\text { FDA) }\end{array}$ & $\begin{array}{l}\text { BioVex Inc } \\
\text { (subsidiário do } \\
\text { Amgen Inc) }\end{array}$ & $\begin{array}{l}\text { Imlygic (talimogene } \\
\text { laherparepvec, T-Vec, } \\
\text { Oncovex-GMCSF }\end{array}$ & $\begin{array}{l}\text { Herpes vírus oncolítico codificando } \\
\text { GM-CSF, utilizado para tratamento } \\
\text { de melanoma }\end{array}$ & $\begin{array}{l}\text { http://www.fda.gov/ } \\
\text { NewsEvents/Newsroom/ } \\
\text { PressAnnouncements/ } \\
\text { ucm469571.htm }\end{array}$ \\
\hline
\end{tabular}

*Orphan drug status approved by FDA in 2008

SFDA, State Food and Drug Administration of China; BFAD, Bureau of Food and Drugs; EMA-CHMP, European Medicines Agency-Committee for Medicinal Products for Human Use; FDA, Food and Drug Administration, USA.

$\mathrm{O}$ primeiro produto de terapia gênica aprovado para venda no mundo ocidental é o Glybera, um vírus adeno-associado recombinante que carrega uma cópia funcional do gene de lipoproteína lipase ${ }^{27}$. O Glybera chamou atenção para um ponto interessante no campo da terapia gênica: Quanto custa e quem paga a conta da terapia gênica? ${ }^{28}$. Como o Glybera é usado para o tratamento de uma doença extremamente rara, o número de pacientes é muito limitado e o mercado de vendas também é pequeno. Portanto, como poucos pacientes serão tratados, a terapia se torna extremamente cara e o investimento das empresas envolvidas com o desenvolvimento do Glybera não será recuperado através do volume de venda do produto. Foi estimado que o tratamento com Glybera custa em torno de US\$1 milhão/paciente, apesar de parecer um preço proibitivo, é interessante lembrar que o custo anual do tratamento tradicional da deficiência da lipoproteína lipase também é considerável e o paciente precisa receber o tratamento durante toda sua vida. A terapia gênica com Glybera é aplicada apenas uma vez e não há necessidade de outros tratamentos e gastos. Uma proposta para solucionar esta situação foi o pagamento anual, enquanto a terapia gênica estiver funcionando e no caso do paciente precisar de outros tratamentos o pagamento seria interrompido.
Assim, o preço ficaria mais acessível para os pacientes, sistemas públicos e convênios de saúde ${ }^{27}$.

Obviamente, as abordagens de terapia gênica vão se mover de doenças raras, incuráveis ou fatais na direção do tratamento de doenças mais comuns, para as quais existem intervenções médicas. Uma das consequências desde novo direcionamento é que a terapia gênica poderá ser acessível a um grupo maior de pacientes. Do ponto de vista de protocolos clínicos experimentais, as principais mudanças estão na análise risco-benefício-custo, tamanho do estudo e escolha de indicação. O efeito da oferta de terapia gênica para número maior de pacientes é sensivelmente observado nos protocolos voltados para o tratamento do câncer. É indiscutível o grande desafio que o tratamento do câncer impõe e o investimento científico em novas terapias anticâncer, como a terapia gênica, não pode ser ignorado. Hoje $67 \%$ e $100 \%$ respectivamente, de todos os protocolos clínicos de terapia gênica em fases III e IV têm como alvo o tratamento do câncer (http://www.abedia.com/wiley/), uma doença multigênica complexa.

O dinamismo, versatilidade e crescimento das tecnologias de transferência gênica também alcançaram os protocolos de terapia celular e hoje são ferramentas complementares e seguras que podem ser exploradas para 
o tratamento de diversas patologias, especialmente no campo da medicina regenerativa envolvendo o uso clínico de IPS (Inducible Pluripotent Stem Cells). Administração nos pacientes de células geneticamente modificadas ex vivo é a via de aplicação frequentemente utilizada nos ensaios clínicos e tem popularizado a terapia gênica.

\section{Problemas encontrados}

O desenvolvimento de uma nova abordagem terapêutica vem com o risco de que o tratamento não seja bem tolerado pelo paciente. No histórico de protocolos clínicos de terapia gênica, englobando todos os vetores, doenças e milhares de pacientes tratados, existem apenas 15 casos de efeitos adversos severos relacionados com o procedimento ${ }^{29}$, são eles: uma morte decorrente de dosagem excessiva de adenovírus e 14 casos de leucemia, incluindo uma morte, associada ao uso de retrovírus. Não querendo diminuir a seriedade do problema ou o sofrimento dos pacientes e suas famílias, mas quando consideramos a gama de abordagens e o grande número de pacientes submetidos à terapia gênica, este número de casos adversos é muito pequeno.

Em termos gerais, os efeitos adversos derivam da biologia do vetor utilizado para a transferência gênica. $\mathrm{O}$ caso da morte de um paciente tratado com adenovírus foi consequência de dosagem extremamente alta $\left(6 \times 10^{13}\right.$ partículas virais) o que levou a uma resposta imunológica intensa e óbito devido a choque anafilático ${ }^{30,31}$. Ressalta- se que este foi o único paciente que teve este tipo de resposta à terapia gênica com adenovírus. $\mathrm{O}$ evento mostrou para os pesquisadores que existe uma dosagem máxima considerada como segura, em outras palavras, a solução para o problema é bem simples: usar dosagens menores.

Infelizmente, nos pacientes que desenvolveram quadro de leucemia o problema foi o retrovírus (gamaretrovírus, onco-retrovírus) utilizado na época do protocolo, que pertence à mesma família de vírus que causa leucemia em murinos, mas até aquele momento nunca tinha sido descrito que o vetor recombinante e incapaz de replicar podia causar leucemia em humanos. Porém, logo foi demonstrado que o vírus não replicativo podia sim causar leucemia em camundongos quando acompanhados por tempo prolongado ${ }^{32}$. Na verdade o que desencadeou o quadro de leucemia foi a inserção de uma estrutura do genoma retroviral, conhecida como LTR (Long Terminal Repeat), na vizinhança de um oncogene ${ }^{33}$. O LTR possui sequências enhancer e pode atuar como um promotor e ativar a expressão de genes do hospedeiro. Avaliação mais precisa da integração de retrovírus no genoma dos pacientes afetados revelou uma tendência do retrovírus utilizado para integrar perto do sítio de iniciação transcricional de genes celulares, no caso o LTR viral se posicionou perto de um oncogene e a ativação do LTR promoveu o início do processo de transformação celular, um fenômeno conhecido como mutagênese insercional ${ }^{34}$.

A solução encontrada, até agora, para mutagênese insercional foi substituir o vetor retroviral por vetor lentiviral. O lentivírus também é um retrovírus, mas pertence à família de HIV (human immunodeficiency virus) e tem um perfil de integração diferente dos gamaretrovírus utilizados nos tratamentos de imunodeficiências. Os lentivírus preferem integrar ao longo de gene celular e não perto de promotores, diminuindo o risco de que o vírus provoque mutagênese insercional ${ }^{33,34}$. Os vetores lentivirais que estão sendo utilizados nos ensaios de terapia gênica são modificados para não conter sequência enhancer viral no seu LTR e a regulação da expressão do gene terapêutico é realizada por um promotor que também não possui ação enhancer, como o promotor EF1 $\alpha$ (elongation factor $1 \alpha)^{35}$. Entre a biologia e o desenho, os vetores lentivirais são considerados mais seguros do que os vetores retrovirais ${ }^{36,37}$. Novamente, a solução para um problema sério é na realidade bem simples: utilizar vetores lentivirais e não retrovirais. E esta é a tendência atual para a modificação genética de célula tronco hematopoiética.

\section{Integração básico-clínica}

Terapia gênica usa genes para curar doenças. $\mathrm{O}$ racional da terapia gênica é uma linha reta: inserir o gene terapêutico em um vetor de transferência gênica e transduzir as células do paciente. $\mathrm{O}$ vetor age como um "remédio" e logo que atinge o alvo começa a direcionar a síntese de uma nova proteína que propriamente restaura um processo celular defeituoso, sem efeito adverso. Apesar de terapia gênica seguir uma rota direta e ser a mais evidente e desejada aplicação clínica da tecnologia do DNA recombinante, ainda é um tratamento majoritariamente experimental e dentro de uma área muito complicada. A alma do tratamento é o vetor de transferência gênica, à medida que uma nova geração de vetores surge, as expectativas de sucesso aumentam.

Os ensaios de terapia gênica nasceram praticamente em paralelo com os avanços na manipulação de genes. Apesar de não restarem dúvidas de que a terapia gênica é o alvo crucial de todo o conhecimento genômico, existe um óbvio descompasso entre uso de genes para diagnosticar doenças (genotipagem) e o uso de genes na terapêutica (terapia gênica). A genotipagem foi rapidamente incorporada pela clínica médica e tem levado a diagnósticos cada vez mais precisos, entretanto os recursos para intervenção terapêutica utilizando genes ainda não são oferecidos fora de protocolos clínicos experimentais. Em outras palavras, genes de diagnóstico são ferramentas de rotina da medicina contemporânea, mas o mesmo não acontece com os genes/vetores terapêuticos. $\mathrm{O}$ mais próximo que o conhecimento do genótipo do paciente se aproxima de condutas terapêuticas é associação de efeito benéfico ou não de um medicamento com a 
presença de algum marcador genético. Recentemente, o FDA estabeleceu como norma que bulas e rótulos de medicamentos alertem sobre o risco ligado a presença de um marcador genético. Uma das consequências desta iniciativa é o estímulo da indústria da genotipagem.

Protocolos clínicos experimentais de terapia gênica fazem parte do portfólio de pesquisa médica translacional de praticamente todos os centros que lideram o desenvolvimento e inovação na medicina. A implementação de um protocolo clínico de terapia gênica requer o desenvolvimento coordenado de uma ampla variedade de novas tecnologias e o estabelecimento de versáteis interações multidisciplinares tanto clínicas quanto básicas. A integração básico-clínica é constante nos estudos de terapia gênica, não apenas com participações pontuais do corpo de pesquisadores básicos ou clínicos. A equipe atua de modo coordenado e todos são envolvidos com as diversas etapas do protocolo clínico experimental, na verdade o envolvimento começa com os experimentos de prova de princípio, onde vetor, gene terapêutico e rota de administração são escolhidos, persiste na fase de scale up de produção de vetores virais com qualidade farmacêutica e finalmente alcança a proposta, execução e avalição de protocolos clínicos experimentais.

Disciplinas acadêmicas com foco em terapia gênica fazem parte de atividades curriculares e extracurriculares das escolas de medicina dos EUA e Europa. Os estudantes recebem formação/treinamento básico, desde o desenho e escolha de vetores até ensaios pré-clínicos e clínicos. Programas de pós-graduação em terapia gênica também permeiam quase todas as áreas de formação médica e são essenciais para a execução de ensaios clínicos em praticamente todas as especialidades da medicina, como genética, pediatria, oncologia, cardiologia, neurologia, hematologia, entre outras.

A visão de terapia gênica na educação médica há muito tempo deixou de ser futurista, do tipo ficção científica, hoje é uma disciplina específica. Um fator essencial e indispensável é o aprendizado de como e quando prescrever um "medicamento" de terapia gênica. Existem claras diferenças entre a prescrição de um fármaco clássico e um vetor de terapia gênica. Em uma breve análise, administrar um vetor terapêutico é basicamente uma intervenção, o vetor "medicamento" age diretamente no genoma, altera a expressão gênica e tem potencial para curar a doença com apenas uma aplicação, não existe uso crônico de um vetor terapêutico. O corpo clínico precisa estar preparado e seguro mantendo constante comunicação entre pesquisadores básicos, pacientes e agências reguladoras.

No cenário atual os protocolos de terapia gênica são ainda experimentais e o esperado é que gere conhecimentos novos, incluindo a identificação de oportunidades para melhorar a abordagem. Neste sentido, é crítico que as observações clínicas sejam transmitidas para a equipe que trata dos estudos básicos, assim reiniciando o ciclo de experimentação no laboratório. Porém, agora a visão inclui o aperfeiçoamento do vetor, gene terapêutico e método de sua aplicação no paciente. Ou seja, a integração dos conhecimentos é essencial para percorrer o caminho de mão dupla: laboratório -> leito do paciente e de volta leito do paciente -> laboratório.

\section{Perspectivas (Brasil e além)}

Terapia gênica é um campo em fase de maturação, a maioria dos protocolos registrados ainda é para ensaios fase inicial: 78\% são de fase I e Fase I / II. Quando os estudos são levados adiante, com base em dados obtidos em experimentos de provas de princípio e modelos animais das ciências básicas o campo se move para frente em direção de protocolos clínicos de cura. É uma excelente oportunidade para o Brasil avançar com o desenvolvimento de uma nova terapia e ultrapassar desafios técnicos. É evidente que séries mais generalizadas de testes bem sucedidos são essenciais para viabilizar a incorporação da terapia gênica na clínica médica mundial, mas os profissionais nacionais precisam estar preparados para lidar com este novo procedimento.

No contexto geral, a medicina translacional no Brasil sofre com sua curta história e são escassos os exemplos de medicamentos concebidos e desenvolvidos no país. Esta situação surpreende porque o país dispõe de conhecimento e tecnologia para desenvolver e testar terapias experimentais.

No caso de terapia gênica, pesquisadores brasileiros já realizaram protocolos clínicos envolvendo transferência gênica com vetores não-virais e têm participado em protocolos multicêntricos internacionais ${ }^{38-41}$. Os próprios pesquisadores neste campo tem se organizado em rede, como é o caso do Instituto do Milênio (2005-2008), INCT (Instituto Nacional de Ciência e Tecnologia, aprovado no mérito, 2010) e com recentes propostas ao INCT que atualmente está em análise (dezembro/2015). O movimento dos pesquisadores e seus resultados têm atraído a atenção internacional da ASGCT (American Society of Gene and Cell Therapy) que está procurando se aproximar de profissionais latino-americanos ${ }^{42}$.

O que falta para que os ensaios clínicos de terapia gênica nacionais alcancem a frequência relativamente próxima a de outros países? Entre os principais desafios estão: (i) a disponibilidade de infraestrutura para produção de vetores recombinantes em condições GMP (Good Manufacturing Practices), condição essencial para aplicação de vetores em pacientes, (ii) clínicos especializados e dedicados para este fim e (iii) ainda a padronização de processo regulatório e de governança sobre os trabalhos com terapia gênica. Porém, estes obstáculos já foram ultrapassados no Brasil, pelo menos quando o assunto não é terapia gênica, o país tem um rico e bem sucedido histórico desenvolvimento de vacinas, trata-se 
de um exemplo a ser emulado.

Outra face que influencia o êxito de um programa de pesquisa em terapia gênica diz respeito aos recursos financeiros necessários. O ideal são mecanismos de financiamento que se estendam desde ensaios de prova de conceito, viabilizem a produção do vetor e o trabalho pré-clínico com modelos animais, chegando até a suportar as travessias das fases iniciais de protocolos clínicos experimentais. Além de financiamento adequado, outros recursos considerados importantes incluem apoio da administração e gerenciamento hospitalar quando da

\section{REFERÊNCIAS}

1. Friedmann T. Stanfield Rogers: insights into virus vectors and failure of an early gene therapy model. Mol Ther. 2001;4(4):285-8. doi: 10.1006/mthe.2001.0454.

2. Cohen SN. DNA cloning: a personal view after 40 years. Proc Natl Acad Sci U S A. 2013;110(39):15521-9. doi: 10.1073/ pnas. 1313397110.

3. Friedmann T, Roblin R. Gene therapy for human genetic disease? Science. 1972;175(25):949-55. Available from: http://www.sciencemag.org/content/175/4025/949.long.

4. Beutler E. The cline affair. Mol Ther. 2001;4(5):396-7. doi: 10.1006/mthe.2001.0486.

5. Blaese RM, Culver KW, Miller AD, Carter CS, FleisherT, Clerici M, Shearer G, Chang L, Chiang Y, Tolstoshev P, Greenblatt JJ, Rosenberg SA, Klein H, Berger M, Mullen CA, Ramsey WJ, Muul L, Morgan RA, Anderson WF. T lymphocyte-directed gene therapy for ADA- SCID: initial trial results after 4 years. Science. 1995;270(5235):47580. Available from: http://www.sciencemag.org/ content/270/5235/475.long.

6. Muul LM, Tuschong LM, Soenen SL, Jagadeesh GJ, Ramsey WJ, Long Z, Carter CS, Garabedian EK, Alleyne M, Brown M, Bernstein W, Schurman SH, Fleisher TA, Leitman SF, Dunbar CE, Blaese RM, Candotti F. Persistence and expression of the adenosine deaminase gene for 12 years and immune reaction to gene transfer components: long-term results of the first clinical gene therapy trial. Blood. 2003;101(7):2563-9. http:// dx.doi.org/10.1182/blood-2002-09-2800.

7. Wiley JS. Gene Therapy Clinical Trials Worldwide - povided by the Journal of Gene Medicine. J Gene Med. 2015 July [cited 2015 julho]. Available from: http://www.abedia.com/ wiley/index.html.

8. Li L, Krymskaya L, Wang J, Henley J, Rao A, et al. Genomic editing of the HIV-1 coreceptor CCR5 in adult hematopoietic stem and progenitor cells using zinc finger nucleases. Mol Ther, 2013;21(6):1259-69. doi:10.1038/ mt.2013.65.

9. Ye L, Wang J, Beyer AI, Teque F, Cradick TJ, Qi Z, Chang JC, Bao G, Muench MO, Yu J, Levy JA, Kan YW. Seamless modification of wild-type induced pluripotent stem cells to the natural CCR5Delta32 mutation confers resistance to HIV infection. Proc Natl Acad Sci U S A, 2014. 111(26): p. 9591-6. execução clínica do estudo e também suporte de instituições e agências regulatórias e maior coerência entre revisões de pequenos ensaios clínicos realizados no ambiente acadêmico.

Talvez um fator que ainda falte, mas que está dentro de nosso alcance, é a via de duas mãos entre os pesquisadores básicos e os clínicos. A natureza multidisciplinar da terapia gênica exige que especialistas com conhecimento pertinente contribuam para o sucesso da proposta. Ou seja, temos todas as peças do quebra cabeça, só falta juntá-las e resolver o problema.

doi: 10.1073/pnas.1407473111.

10. Hsu PD, Lander ES, Zhang F. Development and applications of CRISPR-Cas9 for genome engineering. Cell, 2014;157(6):1262-78. doi: 10.1016/j.cell.2014.05.010.

11. Xu H, Li Z, Si J. Nanocarriers in gene therapy: a review. J Biomed Nanotechnol. 2014;10(12):3483-507. http://dx.doi. org/10.1166/jbn.2014.2044

12. Strauss BE. Vetores para terapia gênica: vìrus, plasmìdeo e outros. Morales M, editor. Terapias avançadas. Rio de Janeiro: Ateneu; 2007. p.121-1478.

13. Manno CS, Pierce GF, Arruda VR, Glader B, Ragni M, Rasko JJ, Ozelo MC, et al. Successful transduction of liver in hemophilia by AAV-Factor IX and limitations imposed by the host immune response. Nat Med. 2006;12(3):342-7. doi: $10.1038 / \mathrm{nm} 1358$.

14. Costanzi-Strauss E, Strauss BE. O ciclo celular como alvo da terapia gênica. Hoff PMG, Chammas R, Odone Filho V, Novis YS, editores. São Paulo: Atheneu; 2013. p.357-81.

15. Cavazzana-Calvo M, Payen E, Negre O, Wang E, Hehir K, Fusil F, Down J, et al. Transfusion independence and HMGA2 activation after gene therapy of human beta-thalassaemia. Nature. 2010;467(7313):318-22. doi: 10.1038/nature09328.

16. Strauss B. Transcriptional control strategies in gene therapy vectors. Xiang J, editor. Development in gene therapy. Kerala, India: Transword Research Network; 2007. p.23-52.

17. Mizuguchi H, Koizumi N, Hosono T, Utoguchi N, Watanabe Y, Kay MA, Hayakawa T. A simplified system for constructing recombinant adenoviral vectors containing heterologous peptides in the HI loop of their fiber knob. Gene Ther. 2001;8(9):730-5. Available from: http://www.nature.com/gt/ journal/v8/n9/full/3301453a.html.

18. Coffin RS. From virotherapy to oncolytic immunotherapy: where are we now? Curr Opin Virol. 2015;13:93-100. doi: 10.1016/j.coviro.2015.06.005.

19. Tong AW, Senzer N, Cerullo V, Templeton NS, Hemminki A, Nemunaitis J. Oncolytic viruses for induction of anti-tumor immunity. Curr Pharm Biotechnol. 2012;13(9):1750-60. doi: 10.2174/138920112800958913\#sthash.efogfqeV.dpuf.

20. Williams DA, Thrasher AJ. Concise review: lessons 
learned from clinical trials of gene therapy in monogenic immunodeficiency diseases. Stem Cells Transl Med. 2014;3(5):636-42. doi: 10.5966/sctm.2013-0206.

21. Cavazzana-Calvo M, Andre-Schmutz I, Fischer A. Haematopoietic stem cell transplantation for SCID patients: where do we stand? Br J Haematol. 2013;160(2):146-52. doi: 10.1111/bjh.12119.

22. Gill S, June CH. Going viral: chimeric antigen receptor T-cell therapy for hematological malignancies. Immunol Rev. 2015;263(1):68-89. doi: 10.1111/imr.12243.

23. Strauss BE, Costanzi-Strauss E. Gene therapy for melanoma: progress and perspectives. Davids LM, editor. Recent advances in the biology: therapy and management of melanoma. InTech Open Science; 2013. Available from: http://onmirror.com/ a87m1r1g81dj/RecentAdvancesBiologyTherapyITO13.pdf. html.

24. Sheridan C. First oncolytic virus edges towards approval in surprise vote. Nat Biotechnol. 2015;33(6):569-70. doi: 10.1038/nbt0615-569.

25. Ma G, Shimada H, Hiroshima K, Tada Y, Suzuki N, Tagawa M. Gene medicine for cancer treatment: commercially available medicine and accumulated clinical data in China. Drug Des Devel Ther. 2009;2:115-22. http://dx.doi.org/10.2147/DDDT. S3535.

26. Li Y, Li LJ, Wang LJ, Zhang Z, Gao N, Liang CY, Huang YD, Han B. Selective intra-arterial infusion of rAd-p53 with chemotherapy for advanced oral cancer: a randomized clinical trial. BMC Med. 2014;12:16. doi: 10.1186/1741-7015-12-16.

27. Bryant LM, Christopher DM, Giles AR, Hinderer C, Rodriguez JL, Smith JB, Traxler EA, Tycko J, Wojno AP, Wilson JM. Lessons learned from the clinical development and market authorization of Glybera. Hum Gene Ther Clin Dev. 2013;24(2):55-64. doi: 10.1089/humc.2013.087.

28. Brennan TA, Wilson JM. The special case of gene therapy pricing. Nat Biotechnol. 2014;32(9):874-6. doi: 10.1038/ nbt.3003.

29. Naldini L. Gene therapy returns to centre stage. Nature. 2015;526(7573):351-60. doi: 10.1038/nature15818.

30. Carmen IH. A death in the laboratory: the politics of the Gelsinger aftermath. Mol Ther. 2001;3(4):425-8. doi: 10.1006/mthe.2001.0305.

31. Somia N, Verma IM. Gene therapy: trials and tribulations. Nat Rev Genet. 2000;1(2):91-9. doi: 10.1038/35038533.

32. Li, Z., Düllmann J, Schiedlmeier B, Schmidt M, von Kalle C, Meyer J, Forster M, Stocking C, Wahlers A, Frank O, Ostertag W, Kühlcke K, Eckert HG, Fehse B, Baum C. Murine leukemia induced by retroviral gene marking. Science. 2002;296(5567):497. DOI: 10.1126/science.1068893.

33. Trono D. Virology. Picking the right spot [comment]. Science. 2003;300(5626):1670-1. doi: 10.1126/science.1086238.

34. Wu X, Li Y, Crise B, Burgess SM. Transcription start regions in the human genome are favored targets for MLV integration. Science. 2003;300(5626):1749-51. doi: 10.1126/ science. 1083413.

35. Baum C, Schambach A, Bohne J, Galla M. Retrovirus vectors: toward the plentivirus? Mol Ther. 2006;13(6):1050-63. doi: 10.1016/j.ymthe.2006.03.007.

36. Montini E, Cesana D, Schmidt M, Sanvito F, Bartholomae CC, Ranzani M, Benedicenti F, Sergi LS, Ambrosi A, Ponzoni M, Doglioni C, Di Serio C, von Kalle C, Naldini L. The genotoxic potential of retroviral vectors is strongly modulated by vector design and integration site selection in a mouse model of HSC gene therapy. J Clin Invest. 2009;119(4):964-75. doi: 10.1172/ JCI37630.

37. Montini E, Cesana D, Schmidt M, Sanvito F, Ponzoni M, Bartholomae C, Sergi Sergi L, Benedicenti F, Ambrosi A, Di Serio C, Doglioni C, von Kalle C, Naldini L. Hematopoietic stem cell gene transfer in a tumor-prone mouse model uncovers low genotoxicity of lentiviral vector integration. Nat Biotechnol. 2006;24(6):687-96. doi: 10.1038/nbt1216.

38. Michaluart P, Abdallah KA, Lima FD, Smith R, Moysés RA, Coelho V, Victora GD, et al. Phase I trial of DNA-hsp65 immunotherapy for advanced squamous cell carcinoma of the head and neck. Cancer Gene Ther. 2008;15(10):676-84. doi: $10.1038 /$ cgt.2008.35.

39. Victora GD, Socorro-Silva A, Volsi EC, Abdallah K, Lima FD, Smith RB, Moyses RA, Zárate-Bladés CR, Michaluart P, Silva CL, Kalil J, Coelho V. Immune response to vaccination with DNA-hsp65 in a phase I clinical trial with head and neck cancer patients. Cancer Gene Ther. 2009;16(7):598-608. doi: 10.1038/cgt.2009.9.

40. Kalil RA, Salles FB, Giusti II, Rodrigues CG, Han SW, Sant'Anna RT, Ludwig E, Grossman G, Prates PR, Sant'anna JR, Teixeira Filho GF, Nardi NB, Nesralla IA. VEGF gene therapy for angiogenesis in refractory angina: phase I/II clinical trial. Rev Bras Cir Cardiovasc. 2010;25(3):311-21. http://dx.doi.org/10.1590/S0102-76382010000300006

41. Pine SO, Kublin JG, Hammer SM, Borgerding J, Huang Y, Casimiro DR, McElrath MJ. Pre-existing adenovirus immunity modifies a complex mixed Th1 and Th2 cytokine response to an Ad5/HIV-1 vaccine candidate in humans. PLoS One. 2011;6(4):e18526. doi: 10.1371/journal.pone.0018526.

42. Breakefield XO. The ASGCT in 2012: charting a path to bring novel biologic therapies to the clinic. Mol Ther. 2012;20(7):1289-90. doi: 10.1038/mt.2012.122.

43. Aiuti A, Cattaneo F, Galimberti S, Benninghoff U, Cassani B, Callegaro L, Scaramuzza S, Andolfi G, Mirolo M, Brigida I, Tabucchi A, Carlucci F, Eibl M, Aker M, Slavin S, Al-Mousa H, Al Ghonaium A, Ferster A, Duppenthaler A, Notarangelo L, Wintergerst U, Buckley RH, Bregni M, Marktel S, Valsecchi MG, Rossi P, Ciceri F, Miniero R, Bordignon C, Roncarolo MG. Gene therapy for immunodeficiency due to adenosine deaminase deficiency. N Engl J Med. 2009;360(5):447-58. doi: 10.1056/NEJMoa0805817.

44. Gaspar HB, Cooray S, Gilmour KC, Parsley KL, Zhang F, Adams S, Bjorkegren E, Bayford J, Brown L, Davies EG, Veys P, Fairbanks L, Bordon V, Petropoulou T, Petropolou T, Kinnon C, Thrasher AJ. Hematopoietic stem cell gene 
therapy for adenosine deaminase-deficient severe combined immunodeficiency leads to long-term immunological recovery and metabolic correction. Sci Transl Med. 2011;3(97):97ra80. doi: 10.1126/scitranslmed.3002716.

45. Candotti F, Shaw KL, Muul L, Carbonaro D, Sokolic R, Choi C, Schurman SH, Garabedian E, Kesserwan C, Jagadeesh GJ, Fu PY, Gschweng E, Cooper A, Tisdale JF, Weinberg KI, Crooks GM, Kapoor N, Shah A, Abdel-Azim H, Yu XJ, Smogorzewska M, Wayne AS, Rosenblatt HM, Davis CM, Hanson C, Rishi RG, Wang X, Gjertson D, Yang OO, Balamurugan A, Bauer G, Ireland JA, Engel BC, Podsakoff GM, Hershfield MS, Blaese RM, Parkman R, Kohn DB. Gene therapy for adenosine deaminase-deficient severe combined immune deficiency: clinical comparison of retroviral vectors and treatment plans. Blood. 2012;120(18):3635-46. doi: 10.1182/blood-2012-02-400937.

46. Gaspar HB. Gene therapy for ADA-SCID: defining the factors for successful outcome. Blood. 2012;120(18):3628-9. doi: 10.1182/blood-2012-08-446559.

47. Zhang L, Thrasher AJ, Gaspar HB. Current progress on gene therapy for primary immunodeficiencies. Gene Ther. 2013;20(10):963-9. doi: 10.1038/gt.2013.21.

48. Strauss BE, Costanzi-Strauss E. Combating oncogene activation associated with retrovirus-mediated gene therapy of X-linked severe combined immunodeficiency. Braz J Med Biol Res. 2007;40(5):601-13. doi: 10.1590/S0100879X2006005000085.

49. Ott MG, Schmidt M, Schwarzwaelder K, Stein S, Siler U, Koehl U, Glimm H, Kuhlcke K, Schilz A, Kunkel H, Naundorf S, Brinkmann A, Deichmann A, Fischer M, Ball C, Pilz I, Dunbar C, Du Y, Jenkins NA, Copeland NG, Luthi U, Hassan M, Thrasher AJ, Hoelzer D, von Kalle C, Seger R, Grez M. Correction of X-linked chronic granulomatous disease by gene therapy, augmented by insertional activation of MDS1-EVI1, PRDM16 or SETBP1. Nat Med. 2006;12(4):401-9. doi:10.1038/nm1393.

50. Hacein-Bey Abina S, Gaspar HB, Blondeau J, Caccavelli L, Charrier S, Buckland K, Picard C, Six E, Himoudi N, Gilmour K, McNicol AM, Hara H, Xu-Bayford J, Rivat C, Touzot F, Mavilio F, Lim A, Treluyer JM, Heritier S, Lefrere F, Magalon J, Pengue-Koyi I, Honnet G, Blanche S, Sherman EA, Male F, Berry C, Malani N, Bushman FD, Fischer A, Thrasher AJ, Galy A, Cavazzana M. Outcomes following gene therapy in patients with severe WiskottAldrich syndrome. JAMA. 2015;313(15):1550-63. doi: 10.1001/jama.2015.3253.

51. Aiuti A, Biasco L, Scaramuzza S, Ferrua F, Cicalese MP, Baricordi C, Dionisio F, Calabria A, Giannelli S, Castiello MC, Bosticardo M, Evangelio C, Assanelli A, Casiraghi M, Di Nunzio S, Callegaro L, Benati C, Rizzardi P, Pellin D, Di Serio C, Schmidt M, Von Kalle C, Gardner J, Mehta N, Neduva V, Dow DJ, Galy A, Miniero R, Finocchi A, Metin A, Banerjee PP, Orange JS, Galimberti S, Valsecchi MG, Biffi A, Montini E, Villa A, Ciceri F, Roncarolo MG, Naldini L. Lentiviral hematopoietic stem cell gene therapy in patients with Wiskott-Aldrich syndrome. Science. 2013;341(6148):1233151. doi: 10.1126/science.1233151.
52. Cavazzana-Calvo M, Payen E, Negre O, Wang G, Hehir K, Fusil F, Down J, Denaro M, Brady T, Westerman K, Cavallesco R, Gillet-Legrand B, Caccavelli L, Sgarra R, Maouche-Chrétien L, Bernaudin F, Girot R, Dorazio R, Mulder GJ, Polack A, Bank A, Soulier J, Larghero J, Kabbara N, Dalle B, Gourmel B, Socie G, Chrétien S, Cartier N, Aubourg P, Fischer A, Cornetta K, Galacteros F, Beuzard Y, Gluckman E, Bushman F, Hacein-Bey-Abina $\mathrm{S}$, Leboulch P. Transfusion independence and HMGA2 activation after gene therapy of human $\beta$-thalassaemia. Nature. 2010;467(7313):318-22. doi: 10.1038/nature09328.

53. Cartier N, Hacein-Bey-Abina S, Bartholomae CC, Veres G, Schmidt M, Kutschera I, Vidaud M, Abel U, Dal-Cortivo L, Caccavelli L, Mahlaoui N, Kiermer V, Mittelstaedt D, Bellesme C, Lahlou N, Lefrere F, Blanche S, Audit M, Payen E, Leboulch P, l'Homme B, Bougneres P, Von Kalle C, Fischer A, Cavazzana-Calvo M, Aubourg P. Hematopoietic stem cell gene therapy with a lentiviral vector in X-linked adrenoleukodystrophy. Science. 2009;326(5954):818-23. doi: 10.1126/science.1171242.

54. Biffi A, Montini E, Lorioli L, Cesani M, Fumagalli F, Plati T, Baldoli C, Martino S, Calabria A, Canale S, Benedicenti F, Vallanti G, Biasco L, Leo S, Kabbara N, Zanetti G, Rizzo WB, Mehta NA, Cicalese MP, Casiraghi M, Boelens JJ, Del Carro U, Dow DJ, Schmidt M, Assanelli A, Neduva V, Di Serio C, Stupka E, Gardner J, von Kalle C, Bordignon C, Ciceri F, Rovelli A, Roncarolo MG, Aiuti A, Sessa M, Naldini L. Lentiviral hematopoietic stem cell gene therapy benefits metachromatic leukodystrophy. Science. 2013;341(6148):1233158. doi: 10.1126/science.1233158.

55. Sheridan C. First oncolytic virus edges towards approval in surprise vote. Nat Biotechnol. 2015;33(6):569-70. doi: 10.1038/nbt0615-569.

56. Andtbacka RH, Kaufman HL, Collichio F, Amatruda T, Senzer N, Chesney J, Delman KA, Spitler LE, Puzanov I, Agarwala SS, Milhem M, Cranmer L, Curti B, Lewis K, Ross M, Guthrie T, Linette GP, Daniels GA, Harrington K, Middleton MR, Miller WH, Jr., Zager JS, Ye Y, Yao B, Li A, Doleman S, VanderWalde A, Gansert J, Coffin RS. Talimogene Laherparepvec Improves Durable Response Rate in Patients With Advanced Melanoma. J Clin Oncol. 2015;33(25):2780-8. doi: 10.1200/JCO.2014.58.3377.

57. Bainbridge JW, Mehat MS, Sundaram V, Robbie SJ, Barker SE, Ripamonti C, Georgiadis A, Mowat FM, Beattie SG, Gardner PJ, Feathers KL, Luong VA, Yzer S, Balaggan K, Viswanathan A, de Ravel TJ, Casteels I, Holder GE, Tyler N, Fitzke FW, Weleber RG, Nardini M, Moore AT, Thompson DA, Petersen-Jones SM, Michaelides M, van den Born LI, Stockman A, Smith AJ, Rubin G, Ali RR. Long-term effect of gene therapy on Leber's congenital amaurosis. N Engl J Med. 2015;372(20):1887-97. doi: 10.1056/NEJMoa1414221.

58. Maguire AM, High KA, Auricchio A, Wright JF, Pierce EA, Testa F, Mingozzi F, Bennicelli JL, Ying GS, Rossi S, Fulton A, Marshall KA, Banfi S, Chung DC, Morgan JI, Hauck B, Zelenaia O, Zhu X, Raffini L, Coppieters F, De Baere E, Shindler KS, Volpe NJ, Surace EM, Acerra C, Lyubarsky A, Redmond TM, Stone E, Sun J, McDonnell JW, Leroy 
BP, Simonelli F, Bennett J. Age-dependent effects of RPE65 gene therapy for Leber's congenital amaurosis: a phase 1 dose-escalation trial. Lancet. 2009;374(9701):1597-605. doi: 10.1016/S0140-6736(09)61836-5.

59. Maude SL, Frey N, Shaw PA, Aplenc R, Barrett DM, Bunin NJ, Chew A, Gonzalez VE, Zheng Z, Lacey SF, Mahnke YD, Melenhorst JJ, Rheingold SR, Shen A, Teachey DT, Levine BL, June CH, Porter DL, Grupp SA. Chimeric antigen receptor $\mathrm{T}$ cells for sustained remissions in leukemia. $\mathrm{N}$ Engl $\mathrm{J}$ Med. 2014;371(16):1507-17. doi: 10.1056/NEJMoa1407222.

60. Chicaybam L, Bonamino MH. Moving receptor redirected adoptive cell therapy toward fine tuning of antitumor responses. Int Rev Immunol. 2014;33(5):402-16. doi: 10.3109/08830185.2014.917412.

61. Jia H, Kling J. China offers alternative gateway for experimental drugs. Nat Biotechnol. 2006;24(2):117-8. doi:10.1038/nbt0206-117.

62. Peng Z, Yu Q, Bao L. The application of gene therapy in
China. IDrugs. 2008;11(5):346-50. Available from: http:// www.ncbi.nlm.nih.gov/pubmed/18465676.

63. Gordon EM, Hall FL. Noteworthy clinical case studies in cancer gene therapy: tumor-targeted Rexin-G advances as an efficacious anti-cancer agent. Int J Oncol. 2010;36(6):134153. doi: 10.3892/ijo_00000619.

64. Gordon EM, Hall FL. Rexin-G, a targeted genetic medicine for cancer. Expert Opin Biol Ther. 2010;10(5):819-32. doi:1 $0.1517 / 14712598.2010 .481666$.

65. Miller N. Glybera and the future of gene therapy in the European Union. Nat Rev Drug Discov. 2012;11(5):419. doi: $10.1038 / \operatorname{nrd} 3572$.

66. Burnett JR, Hooper AJ. Alipogene tiparvovec, an adenoassociated virus encoding the $\operatorname{Ser}(447) \mathrm{X}$ variant of the human lipoprotein lipase gene for the treatment of patients with lipoprotein lipase deficiency. Curr Opin Mol Ther. 2009;11(6):681-91. Disponível em http://www.ncbi.nlm.nih. gov/pubmed/20072945. 